\title{
THREE DIMENSIONAL ATOM PROBE STUDY OF NI-BASE ALLOY/LOW ALLOY STEEL DISSIMILAR METAL WELD INTERFACES
}

\author{
KYOUNG JOON CHOI, SANG HUN SHIN, JONG JIN KIM, JU ANG JUNG, and JI HYUN KIM* \\ Interdisciplinary School of Green Energy, Ulsan National Institute of Science and Technology (UNIST) \\ Ulju-gun, Ulsan Metropolitan City 689-798, Republic of Korea \\ "Corresponding author. E-mail : kimjh@unist.ac.kr
}

Received March 12, 2012

Accepted for Publication April 09, 2012

Three dimensional atom probe tomography (3D APT) is applied to characterize the dissimilar metal joint which was welded between the Ni-based alloy, Alloy 690 and the low alloy steel, A533 Gr. B, with Alloy 152 filler metal. While there is some difficulty in preparing the specimen for the analysis, the 3D APT has a truly quantitative analytical capability to characterize nanometer scale particles in metallic materials, thus its application to the microstructural analysis in multicomponent metallic materials provides critical information on the mechanism of nanoscale microstructural evolution. In this study, the procedure for 3D APT specimen preparation was established, and those for dissimilar metal weld interface were prepared near the fusion boundary by a focused ion beam. The result of the analysis in this study showed the precipitation of chromium carbides near the fusion boundary between A533 Gr. B and Alloy 152.

KEYWORDS : Three Dimensional Atom Probe Tomography, Dissimilar Metal Weld, A533 Gr. B, Alloy 152, Fusion Boundary, Precipitation

\section{INTRODUCTION}

Dissimilar metal welds (DMWs) constitute both material and structural discontinuities in structural components, such as reactor pressure vessels and pressurizer nozzles in nuclear power plants. Between the bulk low alloy steel and filler metal, there exists a transition zone that has a complicated microstructure and chemical composition compared to those in the parent material. Due to the high susceptibility of both the heat affected zone (HAZ) and the fusion boundary (FB) to stress corrosion cracking in combination with thermal aging, concerns have been raised as to the integrity and reliability in the joint transition zone of structural components [1-4].

In terms of DMW characteristics $[1,2,5]$, there is the composition gradient from the base metal to the weld metal across the FB. Such a gradient causes a change in the microstructure and mechanical property, as well as the corrosion resistance. Since the DMW is exposed to thermal cycling during welding $[2,6]$, this thermal cycling makes the change in the microstructure, mechanical properties and corrosion resistance. Due to the microstructure heterogeneity and the thermal mismatch, the formation of residual stress in the FB region can result in the gradient of mechanical properties across the FB [7].

As the key parameters, which affect the stress corrosion cracking, are the material microstructure and chemical composition gradient from the base metal to the weld metal across the FB, it is necessary to fundamentally understand this unique microstructure, in order to improve the understanding of stress corrosion cracking at the FB region. Despite the potential degradation and consequent risk in the DMW [1, 8, 9], there is still a lack of fundamental understanding of the microstructure across the FB region, but particularly in the region containing unidentified band structures near the FB.

The scale of the microstructure in modern metallic materials is becoming increasingly smaller. Until recently, discussion of microstructures in such a small dimension was based only on crystallographic structures, and the chemical natures relevant to those structures were inaccessible. Remarkable advances were made in the analytical capability of transmission electron microscopes, but chemical analysis using a focused electron beam always has limitations, due to the convolution effect when analyzing nanoscale particles embedded in the matrix phase. In many cases, the electron energy loss spectroscopy does not provide quantitative information about light elements from small regions, as metallurgists would expect. The 3-dimensional atom probe tomography (3D APT) has a truly quantitative analytical capability to characterize nanometer scale particles in metallic materials, thus its application to the microstructural 
analysis in multi-component metallic materials provides critical information on the mechanism of nanoscale microstructural evolution [10]. The 3D APT is a microscope that allows the reconstruction of 3D "atom maps" [11]. These reconstructions can be interrogated and interpreted to determine the nanoscale chemistry of the material. For example, a grain boundary in a pressure vessel steel (Fe0.5 at. $\% \mathrm{Cu}-1.5$ at. $\% \mathrm{Ni}-1.5$ at. $\% \mathrm{Mn}-0.75$ at. $\% \mathrm{Si}$ ) aged at $365^{\circ} \mathrm{C}$ for $49,800 \mathrm{~h}$ was examined by the $3 \mathrm{D}$ APT. The tool clearly showed not only $\mathrm{Cu}$ precipitates at the boundary (and one within a grain), but also the segregation of $\mathrm{Mn}$ to the boundary between the precipitates [12]. In addition, the nanoscale chemistry such as precipitate, or grain boundary solute segregation was measured by $3 \mathrm{D}$ APT [11-17].

This study is aiming at the establishment of detail procedures for the characterization of dissimilar metal welds, and the analysis of results using 3D APT in order to get a clear understanding of structure and chemistry in the atomic scale of weld interfaces.

\section{EXPERIMENTAL PROCEDURE}

Specimens for atom probe analysis were produced using a multi-stage process as follows. A representative dissimilar weld mock-up made of Alloy 690/Alloy 152/ A533 Gr. B fabricated by Argonne National Laboratory (ANL) was acquired. A533Gr. B was coated with Alloy 152 with shielded metal arc welding, followed by post welding heat treatment at $607 \sim 635^{\circ} \mathrm{C}$ for 3 hours. After the process, the weld joint of Alloy 690 and A533Gr. B was prepared by the shielded metal arc welding method with Alloy 152 fillers. The first weld layer was buttered with a voltage of 25-26 V, a current of 97-102 A, a travel speed of $127 \mathrm{~mm} / \mathrm{min}$, and a maximum heat input of $1.252 \mathrm{KJ} / \mathrm{mm}$. Then, the remainder was welded with the same range of voltage, maximum heat input and travel speed as the initial buttering, but with a current of 97-102 $\mathrm{A}$, and the maximum heat input of $1.437 \mathrm{KJ} / \mathrm{mm}$. During the process, the interpass temperature was kept below $199^{\circ} \mathrm{C}$, and the minimum preheat temperature was $20^{\circ} \mathrm{C}$. The chemical compositions of both metals are shown in
Table 1. The DMW containing the interface and Alloy 152 was cut from the dissimilar weld joint. Fig. 1 shows each region of the DMW part, including the FB, HAZ, dilution zone (DZ), and Type-II boundary. It is known that a Type-II boundary parallels the fusion boundary within a distance of $100 \mu \mathrm{m}$.[9] The material was cut into small samples $13 \mathrm{~mm} \times 13 \mathrm{~mm} \times 2 \mathrm{~mm}$ by the wire cutting method, as shown in Fig. 2. The samples were polished with $\sim 0.05$ um colloidal silica. The specimens were then washed in acetone and kept under vacuum. In the previous study [18], the chromium carbides were observed using a scanning electron microscope, a transmission electron microscope and a secondary ion mass spectrometry analyses in the FB. Thereby, specimens for 3D APT were prepared near the region containing the FB that was represented in the electron microscope images of Fig. 3. After isolating a $10 \mu \mathrm{m} \times 1 \mu \mathrm{m} \times 5 \mu \mathrm{m}$ volume containing the FB [19-21], three specimens were fabricated with an isolated volume by a focused ion beam from a Helios Nanolab 600 Dual Beam. The step-by-step procedure is as follows:

a. First, the position of the FB is located (Fig. 3 and Fig. 4 (a)).

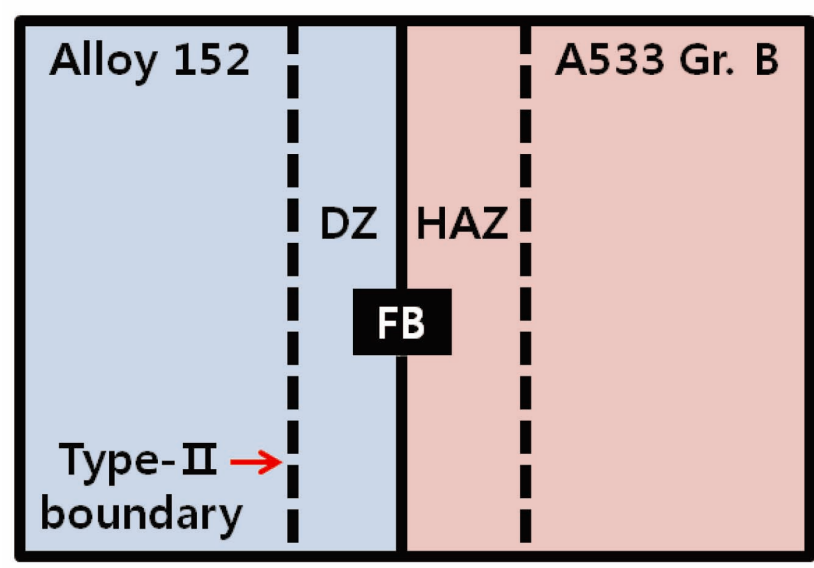

Fig. 1. Schematic of the DMW Part, Including Alloy 152 and A533 Gr. B

Table 1. Chemical Composition (in wt. \%) of Dissimilar Metal Weld used in this Study

\begin{tabular}{|c|c|c|c|c|c|c|c|c|c|c|c|c|c|c|}
\hline \multirow{2}{*}{ Material } & \multicolumn{14}{|c|}{ Composition } \\
\hline & $\mathrm{C}$ & $\mathrm{Al}$ & $\mathrm{Si}$ & $\mathrm{P}$ & $\mathrm{S}$ & $\mathrm{Cr}$ & $\mathrm{Mn}$ & $\mathrm{Fe}$ & $\mathrm{Co}$ & $\mathrm{Ni}$ & $\mathrm{Cu}$ & $\mathrm{Nb}+\mathrm{Ta}$ & Mo & $\mathrm{Ti}$ \\
\hline Alloy 690 & 0.03 & & 0.07 & & $<0.001$ & 29.5 & 0.20 & 9.9 & & 59.5 & 0.01 & & & \\
\hline Alloy 152 & 0.040 & 0.240 & 0.460 & $<0.003$ & $<0.001$ & 29.040 & 3.560 & 9.360 & $<0.01$ & 55.25 & $<0.01$ & 1.84 & 0.01 & 0.15 \\
\hline A533 Gr. B & 0.220 & & 0.19 & 0.010 & 0.012 & 0.18 & 1.28 & & & 0.51 & & & 0.48 & \\
\hline
\end{tabular}


b. Carbon and platinum are deposited in the selected position as Fig. 4 (b).

c. Next, the volume containing the FB is isolated by milling Trench 1 and 2 with Ga ion (Fig. 4 (c)).

d. Sample is tilted by $45^{\circ}$ and the bottom part is cut from the side of Trench 1 (Fig. 4 (c)) by milling box 2, 3 and 4 (Fig. 4 (d)).

e. Sample is rotated by $180^{\circ}$ and tilted by $45^{\circ}$ and the

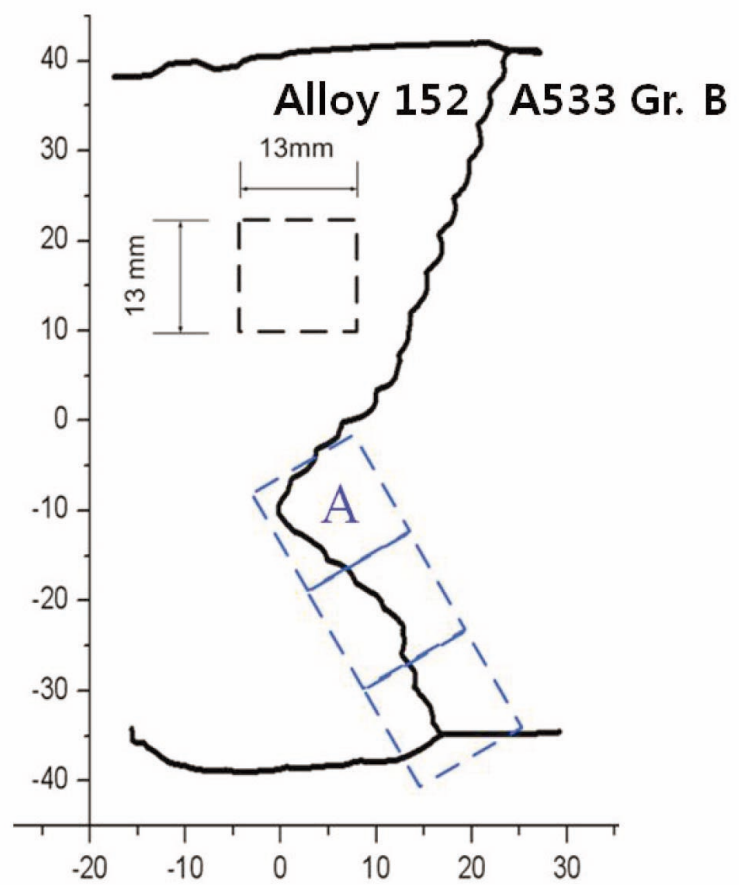

Fig. 2. Sample Location of Alloy690-Alloy152-A533 Gr. B DMW bottom part is cut from the side of Trench 2. (Fig. 4 (c))

f. Step $d$ and e can be repeated with the Ga ion beam in order to isolate the volume containing the FB.

g. Micromanipulator is inserted and positioned so that it touches the corner of the sample near box 1 (Fig. 4 (d)).

$\mathrm{h}$. A platinum box is deposited in order to weld the sample to the micromanipulator.

i. Box 1 is milled in order to fully detach the sample from the bulk (Fig. 4 (d))

j. A tungsten needle is prepared in the same way as a conventional atom probe sample and an array of silicon micro tips $[20,22]$.

$\mathrm{k}$. The part of the detached sample is welded with the tungsten tip by platinum deposition.

1. After the weld process (step k) between the isolated sample and the tungsten tip, a specimen such as Fig. 4 (f) can be achieved by milling box 5 and 6 with the Ga ion beam.

$\mathrm{m}$. The final milling is used to perform the last stage of sharpening, similar to the conventional way $[19,20]$.

$\mathrm{n}$. The end of each specimen is sharpened by applying a series of annular milling patterns along the axis until the required end geometry is achieved, i.e. a tip with a diameter of about $100 \mathrm{~nm}$ and a very low shank angle. Specimens were analyzed using a Cameca LA_WATAP 3D AP for the chemical composition in the region containing the $\mathrm{A} 533 \mathrm{Gr}$. B and the FB. Since the specimen containing some chromium carbides is fragile during the analysis, the laser pulsing method, which can alleviate the problem [11], was used to remove ions from various specimens with a wavelength of $343 \mathrm{~nm}$. For the laser-pulsed, atom-probe specimen, the tips were cooled to a temperature of $60 \mathrm{~K}$. The laser pulse was used with a repetition rate of $100 \mathrm{kHz}$ and voltage of $2 \sim 14 \mathrm{kV}$.

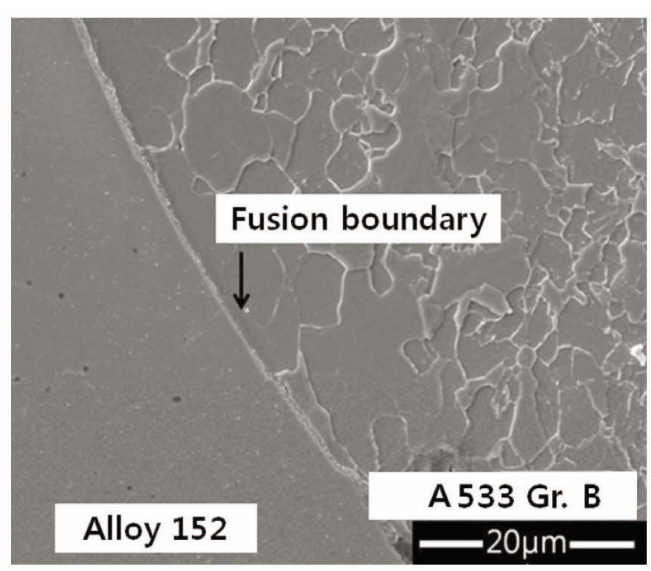

(a)

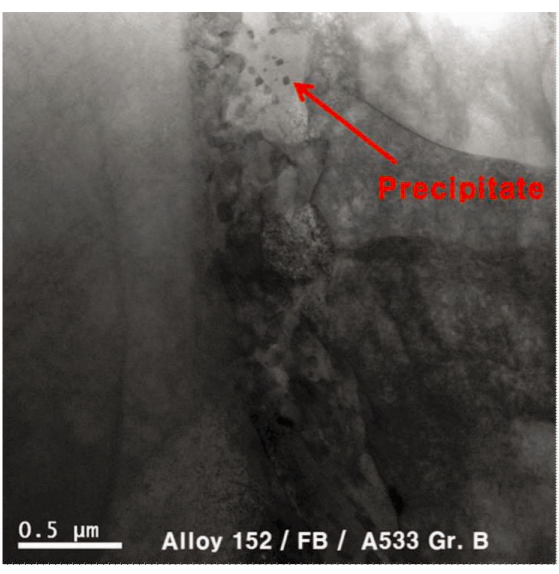

(b)

Fig. 3. Scanning Electron Microscope Image (a) and Transmission Electron Microscope Image (b) of the Fusion Boundary in the Weld Root [18] 


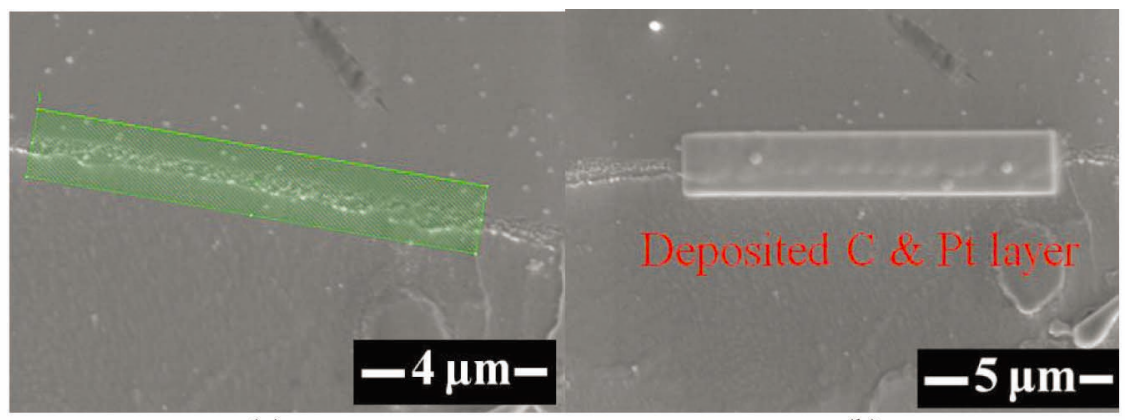

(a)

(b)

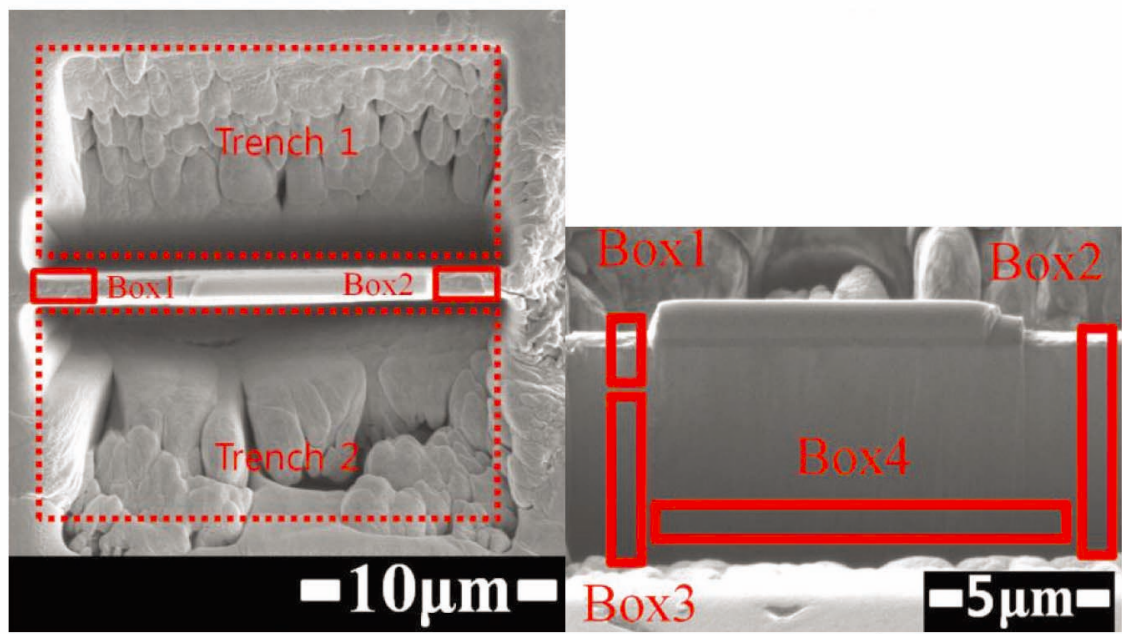

(c)

(d)

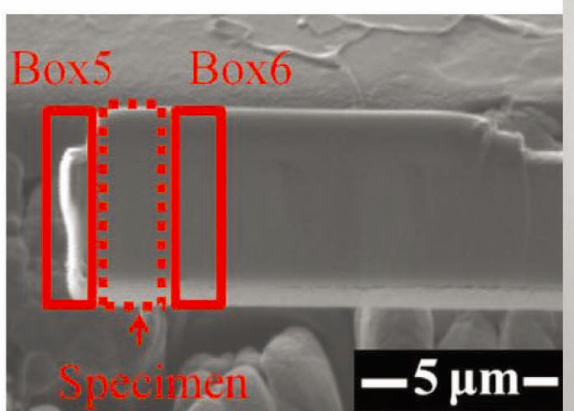

(e)

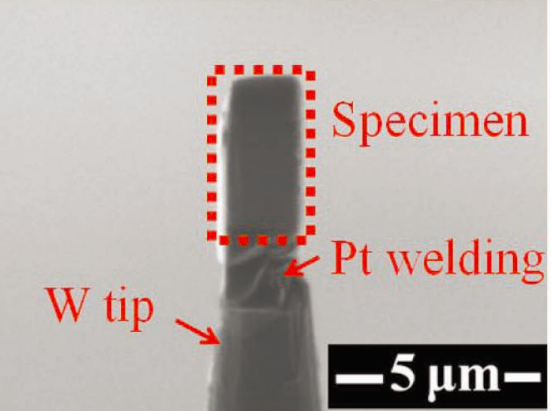

(f)

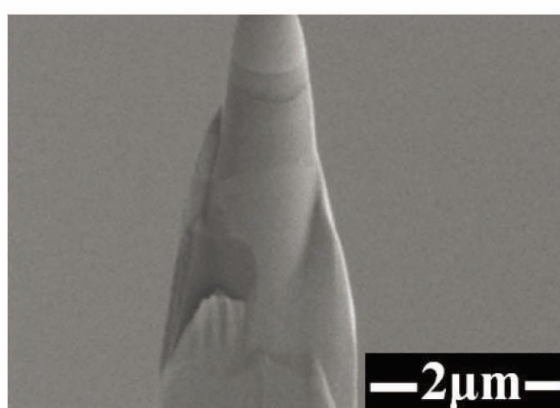

(g)

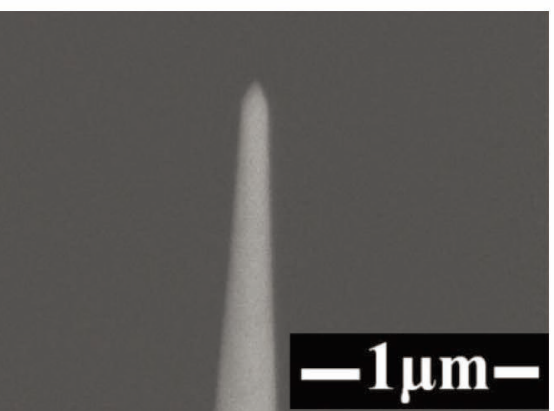

(h)

Fig. 4. Specimen Preparation for 3-D APT, SEM Image from the Area of Interest (a); Platinum and Carbon as Protective Layer (b); Thinned Sample by Gallium Ion (c, d, and e); Attached Sample to W Grid (f); during Annular Milling Patterns (g); Atomprobe Tomography Specimen after Sharpening and the Final Milling (h) 


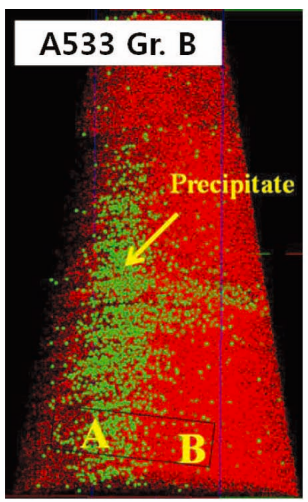

(a)

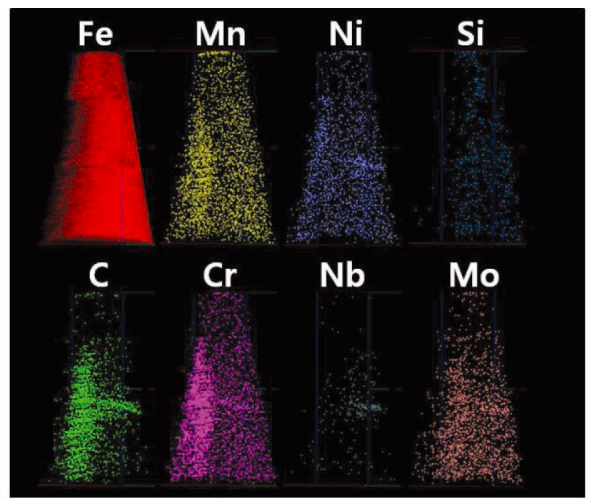

(b)

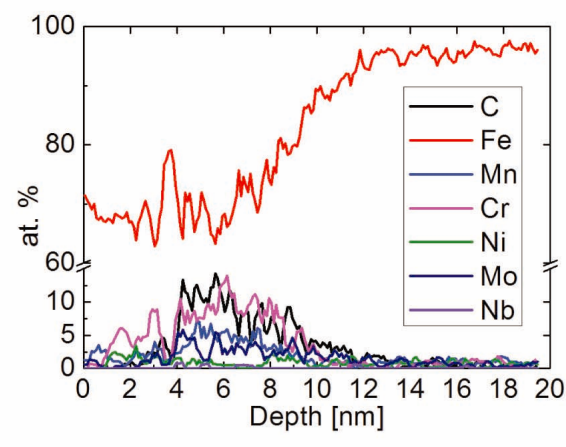

(c)

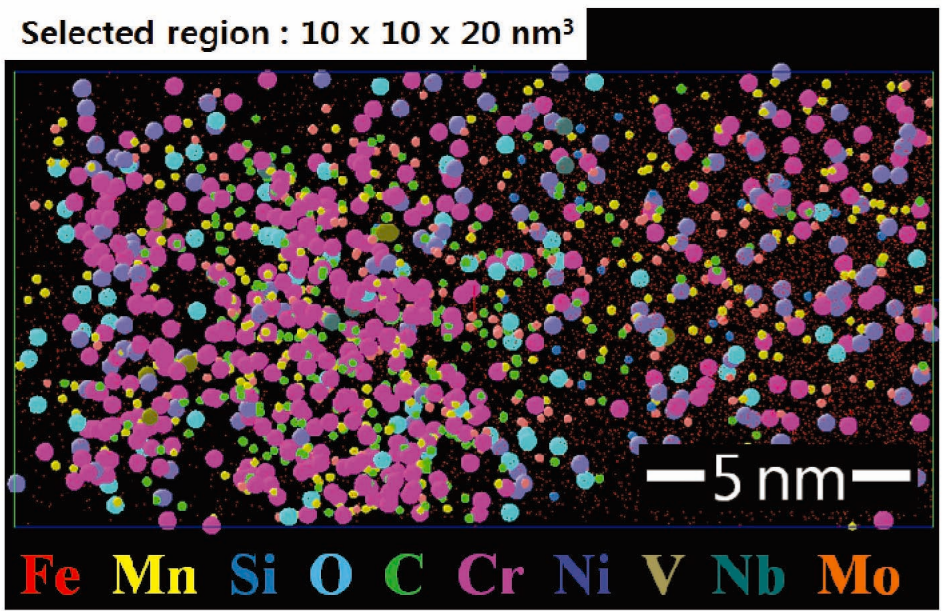

(d)

Fig. 5. Three-dimensional Reconstruction Atomic Map (a) of the DMW Atom Probe Specimen, the Elemental Distributional Map (b) and Atomic Map (d) in the Volume of 'A-B'

\section{RESULT}

All 3D APT analyses were performed near the FB, which is considered to contain chromium carbides, as presented in TEM micrograph of Fig. 3 (b). Fig. 4 illustrated the multi stage process of focused ion beam annular milling, used for atom probe specimen preparation. Since the three analyzed needle specimens (Fig. 4 (h)) were fabricated out of an isolated bulk (Fig. 4 (e)), there exists a slight difference in the analyzed location, which could make a difference in the APT results. The three dimensional atomic maps obtained from the needle specimen with a typical shape as shown Fig. 4 (h), are reconstructed and presented in Figs. 5, 6 and 7. The reconstruction volumes can show $\mathrm{Cr} \& \mathrm{C}$ segregation in the $\mathrm{FB}$, and depletion in either region. In addition, the profiles of the specific elements (such as $\mathrm{Fe}, \mathrm{C}, \mathrm{Cr}, \mathrm{Mn}$ and so on) are observed in the selected region of the three-dimensional reconstructed volumes of these 


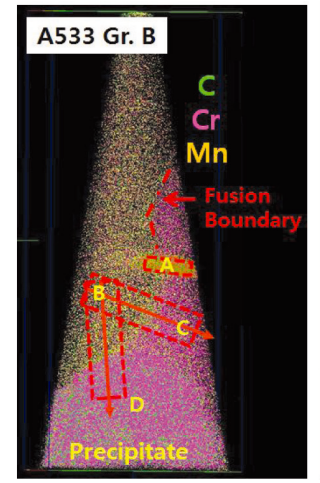

(a)

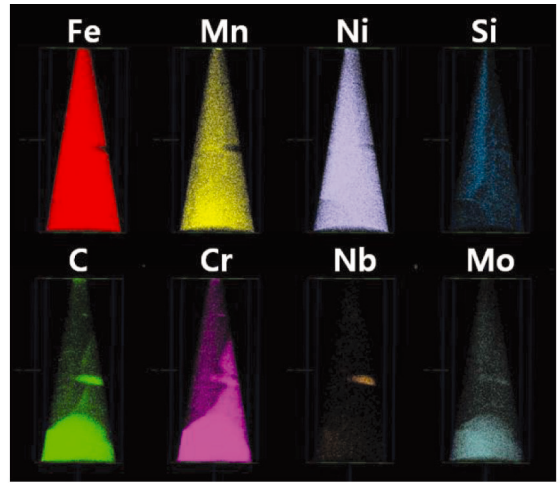

(b)

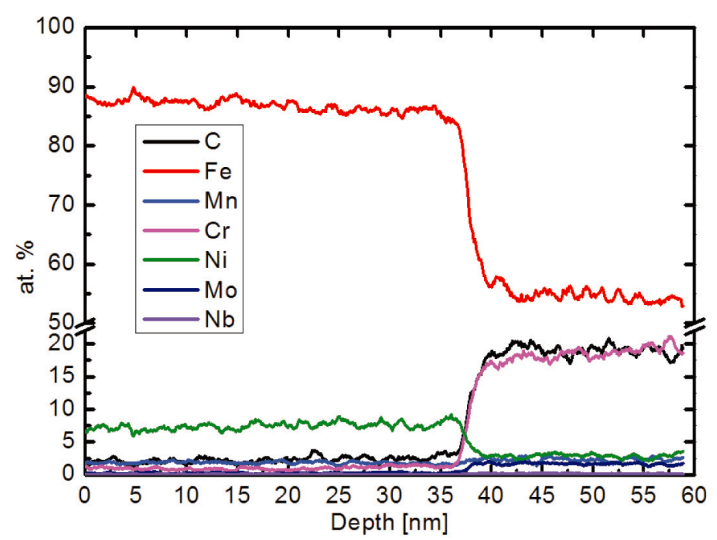

(c)

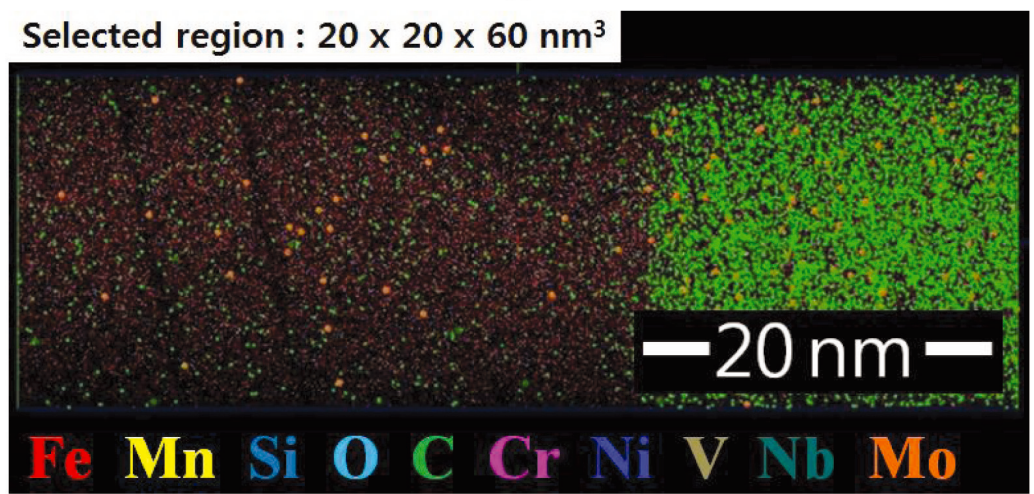

(d)

Fig. 6. Three-dimensional Reconstruction Atomic Map (a) of the DMW Atom Probe Specimen, the Elemental Distributional Map (b) of C, Cr, Mn, Mo, Si, Nb, Fe and Ni Distributions, Elemental Profiles (c) and Atomic Map (d) in the Volume of 'B-D'

figures. These volumes were expressed as a total of each elemental distributional map, including $\mathrm{C}, \mathrm{Cr}, \mathrm{Mn}, \mathrm{Mo}$, $\mathrm{Si}, \mathrm{Fe}$ and $\mathrm{Ni}$.

In this study, three of the specimens prepared by the FIB equipment were successfully analyzed by the 3D APT. Firstly, Figs. 5 (a) and (b) display the three-dimensional reconstruction of the DMW specimens. Since the left band is shown as a precipitate, Figs. 5 (c) and (d) present the profiles and the three dimensional atomic maps, including $\mathrm{Fe}, \mathrm{Mn}, \mathrm{Si}, \mathrm{C}, \mathrm{Cr}$, $\mathrm{Mo}$ and $\mathrm{Ni}$, in the volume containing 'A-B' space. The atomic map was used to calculate the elemental profile. These show that there are higher concentrations of $\mathrm{Cr}, \mathrm{C}$, Mo and $\mathrm{Mn}$, but lower concentrations of Fe near ' $A$ ' than 'B' region. Next, Figs. 6 (a) and (b) show that the reconstructed atomic maps include carbide precipitates in ' $D$ ' region. Similar to Fig. 5 , the elemental profiles in the interesting volume of ' $\mathrm{B}$ D' demonstrate that there are higher concentrations of 


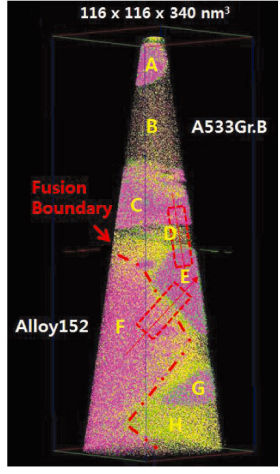

(a)

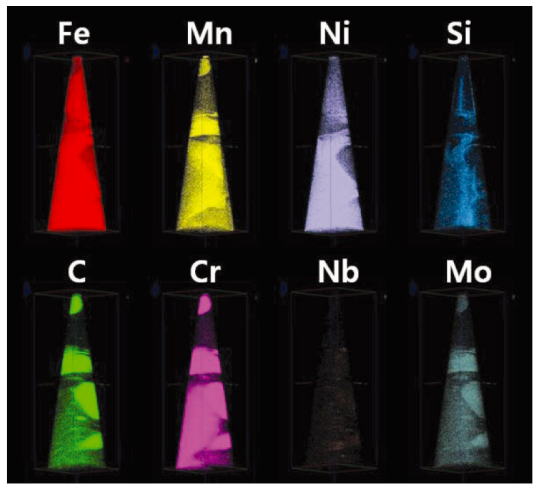

(b)

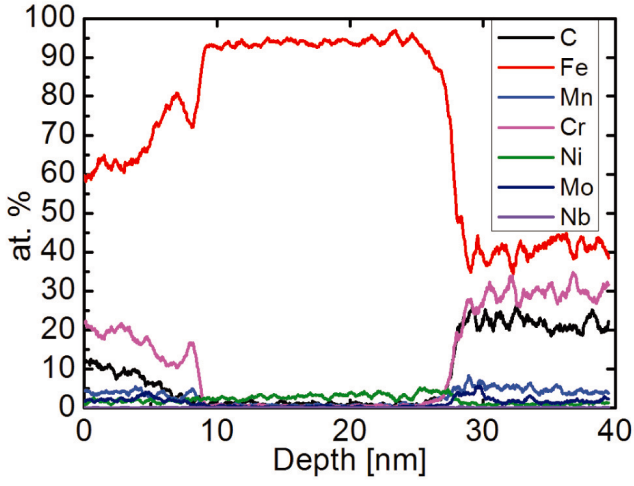

(c)

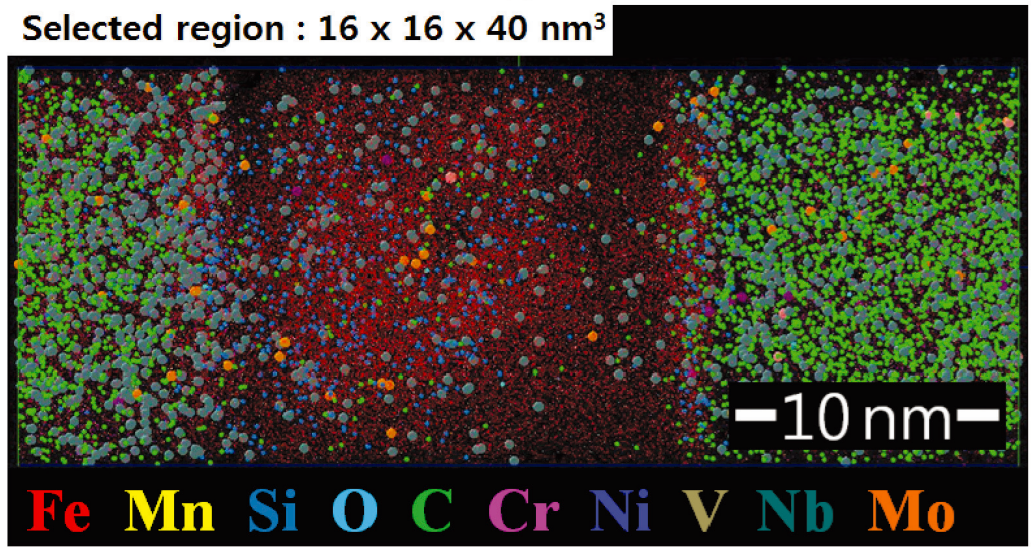

(d)

Fig. 7. Three-dimensional Reconstruction Atomic Map (a) of the DMW Atom Probe Specimen, the Elemental Distributional Map (b) of C, Cr, Mn, Mo, Si, Nb, Fe and Ni Distributions, Elemental Profiles (c) and Atomic Map (d) in the Volume of 'C-D-E'

$\mathrm{Cr}, \mathrm{C}$, Mo and Mn, but lower concentrations of Fe near ' $D$ ' than ' $B$ ' region, in Fig. 6 (c). Through the atomic map in Fig. 6 (d) of the selected volume 'B-D', similar results with the profiles are shown. In addition the left space indicates the carbide precipitate shown in ' $D$ ' region. Lastly, Figs. 7 (a) and (b) are the three dimensional atomic maps, including each of the specific elements. Through the maps, some chromium carbides were observed in A, $\mathrm{C}, \mathrm{E}$ and $\mathrm{G}$ regions. These regions show that the carbon and chromium concentrations are higher, but the iron is lower than the others. On the part including 'C-D-E' of the maps, there are the specific volume's profiles and the atomic map shown in Figs. 7 (c) and (d). As can be seen from the profiles of Fig. 7 (c), it is similarly observed that the carbon and chromium concentrations are relatively high in ' $C$ ' and ' $E$ ' regions. Fig. 7 (d) shows that some precipitates exist in the light ('C') and the left ('E') showing the particularly high concentration of chromium and carbon. 
CHOI et al., Three Dimensional Atom Probe Study of Ni-base Alloy/Low Alloy Steel Dissimilar Metal Weld Interfaces

Table 2. 3D APT Elemental Concentration (in at. \%) in Each Region Indicated in Fig. 5

\begin{tabular}{c|c|c|c|c|c|c|c|c|c|c}
\hline \multirow{2}{*}{ Position } & \multicolumn{10}{c}{ Element } \\
\cline { 2 - 18 } & $\mathrm{Cr}$ & $\mathrm{Mn}$ & $\mathrm{Fe}$ & $\mathrm{Ni}$ & $\mathrm{Mo}$ & $\mathrm{C}$ & $\mathrm{Nb}$ & $\mathrm{Si}$ & $\mathrm{O}$ & $\mathrm{Al}$ \\
\hline $\mathrm{A}$ & 9.460 & 4.836 & 69.040 & 0.607 & 3.394 & 9.870 & 0.244 & 0.013 & - & - \\
\hline $\mathrm{B}$ & 0.839 & 1.040 & 95.653 & 0.712 & 0.699 & 0.028 & 0.028 & 0.136 & - & - \\
\hline
\end{tabular}

Table 3. 3D APT Elemental Concentration (in at. \%) in Each Region Indicated in Fig. 6

\begin{tabular}{|c|c|c|c|c|c|c|c|c|c|c|}
\hline \multirow{2}{*}{ Position } & \multicolumn{10}{|c|}{ Element } \\
\hline & $\mathrm{Cr}$ & $\mathrm{Mn}$ & $\mathrm{Fe}$ & $\mathrm{Ni}$ & Mo & $\mathrm{C}$ & $\mathrm{Nb}$ & $\mathrm{Si}$ & $\mathrm{O}$ & $\mathrm{Al}$ \\
\hline A & 16.457 & - & - & 19.347 & 3.392 & 42.211 & 13.819 & 3.769 & - & - \\
\hline B & 0.948 & 1.623 & 87.417 & 6.349 & 0.297 & 1.532 & 0.014 & 1.645 & 0.080 & 0.002 \\
\hline $\mathrm{C}$ & 4.017 & 1.545 & 86.481 & 5.462 & 0.306 & 1.802 & 0.029 & 0.280 & 0.039 & - \\
\hline $\mathrm{D}$ & 25.611 & 2.673 & 49.506 & 1.770 & 2.277 & 17.549 & 0.035 & 0.064 & 0.042 & 0.037 \\
\hline
\end{tabular}

Table 4. 3D APT Elemental Concentration (in at. \%) in Each Region Indicated in Fig. 7

\begin{tabular}{|c|c|c|c|c|c|c|c|c|c|c|}
\hline \multirow{2}{*}{ Position } & \multicolumn{10}{|c|}{ Element } \\
\hline & $\mathrm{Cr}$ & $\mathrm{Mn}$ & $\mathrm{Fe}$ & $\mathrm{Ni}$ & Mo & $\mathrm{C}$ & $\mathrm{Nb}$ & $\mathrm{Si}$ & $\mathrm{O}$ & $\mathrm{Al}$ \\
\hline A & 31.697 & 4.674 & 37.958 & 1.483 & 1.275 & 22.399 & 0.042 & 0.311 & 0.129 & 0.033 \\
\hline B & 0.414 & 0.697 & 95.919 & 1.949 & 0.147 & 0.543 & 0.015 & 0.204 & 0.112 & 0 \\
\hline $\mathrm{C}$ & 29.086 & 6.059 & 41.499 & 1.044 & 2.308 & 19.606 & 0.053 & 0.2 & 0.121 & 0.025 \\
\hline $\mathrm{D}$ & 0.361 & 0.621 & 93.754 & 2.975 & 0.382 & 0.945 & 0.052 & 0.858 & 0.041 & 0.011 \\
\hline $\mathrm{E}$ & 31.717 & 4.621 & 38.21 & 1.112 & 2.118 & 21.801 & 0.08 & 0.208 & 0.086 & 0.028 \\
\hline $\mathrm{F}$ & 4.428 & 1.74 & 84.657 & 5.224 & 0.552 & 2.74 & 0.034 & 0.553 & 0.071 & 0.002 \\
\hline G & 16.674 & 2.179 & 58.207 & 1.839 & 2.459 & 18.07 & 0.292 & 0.174 & 0.071 & 0.035 \\
\hline $\mathrm{H}$ & 0.582 & 0.679 & 92.211 & 3.38 & 0.268 & 1.914 & 0.037 & 0.869 & 0.061 & 0 \\
\hline
\end{tabular}

Tables 2, 3 and 4 summarize the chemical concentrations in the regions containing the precipitates represented in Figs. 5, 6 and 7. As shown in Table 2, it is known that the position ' $A$ ' in Fig. 5(a) corresponds to carbide precipitates which contain higher metallic elemental (except iron) and carbon concentrations compared to those in position B. Table 3 shows that the higher concentrations of $\mathrm{Cr}, \mathrm{C}$, Mo and $\mathrm{Mn}$ are in the region of $\mathrm{D}$ (Fig. 6) and table 4 displays that the higher concentrations of $\mathrm{Cr}, \mathrm{C}, \mathrm{Mo}$ and $\mathrm{Mn}$ are in the regions of A, C, E and G (Fig. 7). As seen from the 3D APT results, these regions can be considered as carbide precipitates, which are formed in A533 Gr. B near the FB during the welding process. As commonly seen in Tables
2 4, higher Mo and $\mathrm{Mn}$ are observed in the area where $\mathrm{Cr}$ and $\mathrm{C}$ concentrations are relatively high. According to Styman et al. [26], C has a very strong attraction for Mo, $\mathrm{Mn}$ and $\mathrm{Cr}$, and so drives the segregation of these elements to the boundary, which in turn drives more $\mathrm{C}$ to the boundary. In addition, Mo has a strong affinity with $\mathrm{P}$ and so drives this to the boundary. In turn, $\mathrm{P}$ drives $\mathrm{Ni}$ along with more $\mathrm{Mn}$ and $\mathrm{Cr}$. In addition, through that, B and D spaces have higher $\mathrm{Fe}$ and lower Ni than F space in Figs 7 (c) and (d), and Table 4. Therefore the FB can also be distinguished from other regions as shown in Fig. 7 (a).

In summary, the regions including some precipitates have higher carbon and chromium concentrations than the 
other regions, which is similar to what was observed with the secondary ion mass spectrometry and transmission electron microscope analyses performed in the previous study [18]. These results can help to distinguish the chemical difference between the precipitates and the others. Thereby, the chromium carbides are formed in Alloy 152 weld metal during the welding process.

\section{DISCUSSION}

In order to evaluate the integrity of the FB between the Alloy 152 filler metal and low alloy steel A533Gr. B in DMW, this study is aiming at the nano-scale characterization by 3D APT, including chemical analysis in HAZ near the FB of DMW. With a clear understanding of the microstructure of the FB region in an Alloy 152-low alloy steel dissimilar weld joint, the results are discussed in this section under the context of the likely effect of long term aging on the potential degradation and cracking in heat affected zones. From the results described in the previous section, it can be summarized that several chromium carbides were observed in the heat-affected zone near the FB. There is a similar, previous study related to the precipitates that Hou et al. [1] performed with Alloy 182 filler metal and A533 Gr. B. They found the existence of a type-II boundary parallel to the FB in the dilution zone of Alloy 182. They observed the precipitates of composite carbides of $\mathrm{Ni}$ and $\mathrm{Nb}$, and $\mathrm{Cr}_{23} \mathrm{C}_{6}$ on the type-II boundary and $\mathrm{FB}$ region, using a transmission electron microscope. There are similar precedents that some precipitates were observed by 3D APT. Miller et al. [23-35] observed copper-, nickel-, manganese- and silicon-enriched precipitates in reactor pressure vessel weld steel and base steel by using 3D APT. They applied the technology of 3D APT to show that the precipitates coarsened during neutron irradiation and post irradiation heat treatment. In addition, Styman et al. [26] found copper-enriched precipitation in long-term, thermally aged high copper and high nickel mode reactor pressure vessel steel welds. As shown in the previous studies, the atom probe is a tool able to analyze nanoscale precipitates. However, there has been little study on the nano-scale characterization of precipitates in the HAZ near the FB in DMWs.

In this study, the chromium carbides were observed and characterized in the HAZ near the FB by analyzing 3D APT. The formation of precipitates can cause the depletion of chromium in the matrix, which may result in less formation of a protective chromium oxide layer in the high temperature aqueous environment. The region in the heat affected zone of A533 Gr. B showed the highest hardness [18]. This characteristic shows that this may have degraded through thermal cycling during the weld process with the combination of high residual stress. When the long-term exposure of this kind of material experiences thermal aging, the aging effects can cause redistribution of chemistry around FB, and consequent effects on mechanical properties. During aging in service, the concentration gradient for the major alloying elements, including $\mathrm{Fe}, \mathrm{Ni}$ and $\mathrm{Cr}$, will not change significantly, because the diffusion rates of these elements are too low. However, the large change in $\mathrm{C}$ concentration, combined with the $\mathrm{Cr}$ concentration gradient, produces a chemical potential gradient that is high in A533 Gr. B, and low in the Alloy 152. This leads to $\mathrm{C}$ migration from the A533 Gr. B toward the $\mathrm{FB}$, and the migration and concomitant enrichment of $\mathrm{C}$ leads to the formation of the carbide precipitates near the FB [27, 28]. Combining all described above, the FB in the DMW can be severely degraded by the decreased resistance to intergranular stress corrosion cracking. However, a detail investigation on the effect of thermal aging on the change of properties in the DMW needs to be pursued to warrant the integrity of DMWs.

\section{CONCLUSION}

By using a three dimensional atom probe tomography (3D APT) and a focused ion beam instrument, nano-scale analyses were performed to understand the structure of the fusion boundary (FB) between the Alloy 152 filler metal and the low alloy steel A533Gr. B in the dissimilar metal weld (DMW). The procedure for 3D APT specimen preparation was practiced and established, and those for the DMW interface were prepared near the FB by a focused ion beam. From the 3D APT analysis in this study, several chromium carbides were observed on the FB. With longterm exposure, this kind of DMW could experience thermal aging, which can cause degradation by grain coarsening, precipitation and the segregation of trace impurities near the FB. However, a detailed investigation of the effect of thermal aging on the change of properties in the DMW needs to be pursued to warrant the integrity of DMWs.

\section{ACKNOWLEDGEMENT}

This work was financially supported by the R\&D Program of the Korea Institute of Energy Technology Evaluation and Planning (KETEP), funded by the Ministry of Knowledge Economy (MKE), and by the Korean Nuclear R\&D program organized by the National Research Foundation (NRF) of Korea in support of the Ministry of Education, Science and Technology (MEST).

\section{REFERENCES}

[1] J. Hou, Q.J. Peng, Y. Takeda, J. Kuniya, T. Shoji, J.Q. Wang, E.H. Han and W. Ke, "Microstructure and mechanical property of the fusion boundary region in an Alloy 182low alloy steel dissimilar weld joint," J. Mater. Sci., vol. 45, pp. 5332 (2010)

[2] M. Sireesha, S.K. Albert, V. Shankar and S. Sundaresan, "A comparative evaluation of welding consumables for dissimilar welds between $316 \mathrm{LN}$ austenitic stainless steel 
and Alloy 800," J. Nucl.Mater., vol. 279, pp. 65 (2000)

[3] J.I. Bennetch, G.E. Modzelewski, L.L. Spain and G.V. Rao, "Root Cause Evaluation and Repair of Alloy 82/182 J-Groove Weld Cracking of Reactor Vessel Head Penetrations at North Anna Unit 2", ASME PVP, vol. 437, pp. 179 (2002)

[4] G.F. Li, J. Congleton, "Stress corrosion cracking of a low alloy steel to stainless steel transition weld in PWR primary waters at 2928C,"Corrosion Sci., vol. 42, pp. 1005 (2000)

[ 5 ] C.H. Jang, J.H. Lee, J.S. Kim and T.E. Jin, "Mechanical Properties Evaluation in Inconel 82/182 Dissimilar Metal Welds," J. PVP, vol. 85, pp. 635 (2008)

[6] J.Y. Koo and A. Ozekcin, Welding Metallurgy of Structure Steels, p. 119, The Metallurgical Society, New Jersey (1987)

[ 7 ] H.T. Lee, S.L. Jeng, C.H. Yen and T.Y. Kuo, "Dissimilar welding of nickel-based Alloy 690 to SUS 304L with Ti addition," J. Nucl. Mater., vol. 335, pp.59 (2004)

[ 8 ] H.P. Seifert, S. Ritter, T. shoji, Q.J. Peng, Y. Takeda and Z.P. Lu, "Environmentally-assisted cracking behaviour in the transition region of an Alloy182/SA $508 \mathrm{Cl} .2$ dissimilar metal weld joint in simulated boiling water reactor normal water chemistry environment," J. Nucl. Mater., vol. 378, pp. 197 (2008)

[9] T.W. Nelson, J.C. Lippold and M.J. Mills, "Nature and Evolution of the Fusion Boundary in Ferritic-Austenitic Dissimilar Metal Welds -Part 2: On-Cooling Transformations," J. Weld, vol. 79, pp. 267 (2000)

[10] K. Hono, "Atom probe microanalysis and nanoscale microstructures in metallic materials" Acta Mater., vol. 47, pp. 3127 (1999)

[11] D. Hudson and G.D.W. Smith, "Initial observation of grain boundary solute segregation in a zirconium alloy (ZIRLO) by three-dimensional atom probe", Scripta Mater., Vol. 61, pp. $411(2009)$

[12] A. Cerezo, P.H. Clifton, S. Lozano-Perez, P. Panayi and G. Sha, "Overview: Recent Progress in Three-Dimensional Atom Probe Instruments and Applications", Microsc. Microanal., vol. 13, pp. 408 (2007)

[13] E.A. Marquis, R. Hu and T. Rousseau, "A systematic approach for the study of radiation-induced segregation/depletion at grain boundaries in steels", J. Nucl. Mater., vol. 413, pp. 1 (2011)

[14] A.R. Waugh, M.J. Southon, "Surface studies with an imaging atom-probe", Surf. Sci., Vol. 68, pp. 79 (1977)

[15] B.W. Krakauer and D.N. Seidman, "Absolute atomic-scale measurements of the Gibbsian interfacial excess of solute at internal interfaces" Phys. Rev. B, Vol. 48, pp. 6724 (1993)

[16] D. Blavette, E. Cadel, C. Pareige, B. Deconihout and P. Caron, "Phase transformation and segregation to lattice defects in Ni-base superalloys", Microsc. Microanal., Vol. 13, pp. 46, (2007)

[17] E.A. Marquis and J.M. Hyde, "Applications of atom-probe tomography to the characterisation of solute behavior", Mater. Sci. Eng. R, Vol. 69, pp. 3, (2010)

[18] K.J. Choi, J.J. Kim and J. H. Kim, "Nano-structural and nano-chemical analysis of Ni-base alloy/low alloy steel dissimilar metal weld interfaces", Nuclear Engineering and Technology (2012), doi: http://dx.doi.org/10.5516/NET .07 .2012 .009

[19] S. Lozano-Perez, "A guide on FIB preparation of samples containing stress corrosion crack tips for TEM and atomprobe analysis”, Micron, vol. 39, pp. 320 (2008)

[20] M.K Miller, K.F. Rusell, "Atom probe specimen preparation with a dual beam SEM/FIB miller", Ultramicroscopy, vol. 107, pp. 761 (2007)

[21] M.K. Miller, K.F. Russell and G.B. Thompson, "Strategies for fabricating atom probe specimens with a dual beam FIB", Ultramicroscopy, Vol. 102, pp. 287 (2005)

[22] K. Thompson, J.H. Booske, D.J. Larson, T.F. Kelly, "Threedimensional atom mapping of dopants in Si nanostructures", Appl. Phys. Lett., vol. 87, pp. 52108-1-3 (2005)

[23] M.K. Miller, M,A, Sokolov, R.K. Nanstad and K.F. Russel, "APT characterization of high nickel RPV steels", J. Nucl. Mater., vol. 351, pp. 187 (2006)

[24] M.K. Miller and K.F. Russell, "Embrittlement of RPV steels: An atom probe tomography perspective", J. Nucl. Mater., vol. 271, pp. 145 (2007)

[25] M.K. Miller, A.A. Chernobaeva, Y.I. Shtrombakh, K.F Russell, R.K. Nanstad, D.Y. Erak and O.O. Zabusov, "Evolution of the nanostructure of VVER-1000 RPV materials under neutron irradiation and post irradiation annealing", J. Nucl. Mater., vol. 385, pp. 615 (2009)

[26] P.D. Styman, J.M. Hyde, K. Wilford, A. Morley and G.D.W. Smith, "Precipitation in long term thermally aged high copper, high nickel model RPV steel welds", Progress in Nuclear Energy Vol. 57, pp. 86 (2012)

[27] J.D. Parker and G.C. Stratford, "Characterization of microstructures in nickel based transition joints," J. Mater. Sci., vol. 35, pp. 4099 (2000)

[28] J.D. Dupont and R. E. Mizia, "Review of Dissimilar Metal Welding for the NGNP Helical-Coil Steam Generator," INL/EXT-10-18459, Idaho National Laboratory (2010) 